\title{
Knockdown of AKR1C3 exposes a potential epigenetic susceptibility in prostate cancer cells.
}

\author{
Craig L Doig ${ }^{\text {af }}$, Sebastiano Battaglia ${ }^{\mathrm{b}}$, Farhat L. Khanim ${ }^{\mathrm{c}}$, \\ Christopher M Bunce ${ }^{\mathrm{c}} \&$ Moray J Campbell ${ }^{\mathrm{b}}$,
}

Short Title: AKR1C3 actions in prostate cancer.

Word count: 4,564 + 6 Figures (including 1 Supplementary)

${ }^{a}$ Centre for Endocrinology Diabetes \& Metabolism, School of Clinical \& Experimental Medicine, University of Birmingham, Edgbaston, B15 2TT, UK

${ }^{b}$ Department of Pharmacology and Therapeutics, Roswell Park Cancer Institute, Buffalo, NY 14263, USA.

${ }^{\mathrm{c}}$ School of Biosciences, University of Birmingham, Edgbaston, B15 2TT, UK

${ }^{\mathrm{f}}$ Corresponding Author. c.l.doig@bham.ac.uk Tel. +44(0)121 4158705 


\begin{abstract}
Background. The aldo-keto reductase 1C3 (AKR1C3) has been heavily implicated in the propagation of prostate malignancy. AKR1C3 protein is elevated within prostate cancer tissue, it contributes to the formation of androgens and downstream stimulation of the androgen receptor (AR). Elevated expression of AKR1C3 is also reported in acute myeloid leukemia but the target nuclear receptors have been identified as members of the PeroxisomeProliferator Activated Receptor (PPARs) subfamily. Thus, AKR1C3 cancer biology is likely to be tissue dependent and hormonally linked to the availability of ligands for both the steroidogenic and non-steroidogenic nuclear receptors.
\end{abstract}

Methods. In the current study we investigated the potential for AKR1C3 to regulate the availability of prostaglandin-derived ligands for PPARg mainly, Prostaglandin $J_{2}\left(\mathrm{PGJ}_{2}\right)$. Using prostate cancer cell lines with stably reduced AKR1C3 levels we examined the impact of AKR1C3 upon proliferation mediated by PPAR ligands.

Results. These studies revealed knockdown of AKR1C3 had no effect upon the sensitivity of androgen receptor independent prostate cancer cells towards PPAR ligands. However, the reduction of levels of AKR1C3 was accompanied by a significantly reduced mRNA expression of a range of HDACs, transcriptional co-regulators, and increased sensitivity towards SAHA, a clinically approved histone deacetylase inhibitor.

Conclusions. These results suggest a hitherto unidentified link between AKR1C3 levels and the epigenetic status in prostate cancer cells. This raises an interesting possibility of a novel rational to target $\mathrm{AKR} 1 \mathrm{C} 3$, the utilization of AKRIC3 selective inhibitors in combination with HDAC inhibition as part of novel epigenetic therapies in androgen deprivation therapy recurrent prostate cancer.

Keywords: Prostate cancer, 17B-Hydroxysteroid dehydrogenase, AKR1C3, PPAR, prostaglandins, Bezafibrate. 


\section{Introduction}

Nuclear Receptors (NRs) regulate multiple gene targets controlling cell growth and differentiation in many self-renewing tissues including hematopoietic and epithelial cells. The ability of NRs to exert these gene regulatory effects is dictated by the supply of ligand availability and epigenetic context (reviewed in ${ }^{1,2}$ ).

Prostate cancer $(\mathrm{CaP})$ represents an attractive disease with which to target NR signaling in either chemoprevention or chemotherapeutic strategies. Early stage disease is a potential target for chemotherapies that target NRs such as VDR, RARs/RXRs and PPARs ${ }^{3-5}$. Expression of these receptors is sustained in early stage $\mathrm{CaP}$ and they are well established as exerting a range of tumor repressive effects. For example, PPARg receptor activation induces anti-proliferative, prodifferentiating gene targets and has subsequently been the target of various clinical trials including a phase II clinical study with Troglitazone ${ }^{6}$. At late stage CaP targeting of the AR by androgen deprivation therapy (ADT) forms the current treatment mainstay for advanced prostate cancer. However, in ADT-R CaP (androgen deprivation therapy - recurrent prostate cancer), is predominantly lethal with limited alternative therapeutic strategies ${ }^{7}$.

In late stage and ADT-R CaP aberrant co-repressor actions preclude NR activation, impairing anti-proliferative capacity and further epigenetic mechanisms contribute to this resistance ${ }^{8}$ with similar events disrupting AR signaling, ${ }^{9,10}$ (reviewed in ${ }^{11}$ ). Specifically, PPARg actions are epigenetically disrupted and can be targeted selectively by using HDAC inhibitor cotreatments $^{12,13}$. Elevated levels of the co-repressors NCOR1, and to a lesser extent NCOR2/SMRT, correlated with, and functionally drive, the selective insensitivity of PPARa/g receptors towards dietary derived and therapeutic ligands ${ }^{13,14}$.

One approach to target $\mathrm{NR}$ signaling in $\mathrm{CaP}$ is to target the enzymes that regulate ligand availability. Aldoketoreductase $1 \mathrm{C} 3$ (AKR1C3) is a multifunctional enzyme and acts as a type 2 3-alpha-Hydroxysteroid dehydrogenase or 17-beta-HSD type 5. A key regulator of steroidal metabolism, it is implicated in cancer progression. For example, silencing of AKR1C3 has been shown to inhibit cervical cancer metastasis ${ }^{15}$. In CaP, AKR1C3 actions are implicated in the generation of androgens ${ }^{16-19}$, AR activation and has been investigated as a potential biomarker for $\mathrm{CaP}$ progression ${ }^{20}{ }^{21}$. However, AKR1C3 is able to convert various different substrates and reflecting this, it has been implicated in the altered metabolism of chemotherapeutics propagating cancer cells resistance ${ }^{22}$. Perhaps reflecting this promiscuity over substrate choice, AKR1C3 is often overexpressed in prostate cancer tissues and prostate cancer cell lines ${ }^{23}$. Furthermore its expression is elevated in cell lines with either absent or low levels of $\mathrm{AR}^{24}$ suggesting that substrates may include those independent of androgen signaling; and $5 \alpha$-Dihydrotestosterone may not be the only product of AKR1C $3^{25,26}$.

Previous publications have considered the regulatory actions of AKR1C3 on alternative substrates, including the arachidonate-derived prostaglandins that act as de novo ligands for PPARg $^{27}$. The expression level of AKR1C3 has been examined in ADT-R CaP tissue and cells lines, including PC-3 and DU 145 cells, and been shown to be elevated compared to less aggressive counterparts and directly proportional to the $11 \mathrm{~b}-\mathrm{PGF}_{2}$ levels ${ }^{28}$. We and others have examined the ability of AKR1C3 to convert prostaglandin $\mathrm{D}_{2}\left(\mathrm{PGD}_{2}\right)$, into 9-alpha, 11betaprostaglandin $\mathrm{F}_{2}{ }^{28,29}$ (a ligand for the $\mathrm{FP}$ receptor, which is a driver of cell proliferation) preventing the alternative spontaneous and non-enzymatic generation of the potent PPARg ligand $\mathrm{PGJ}_{2}{ }^{30,31}$. Additionally, the PPARg mediated protective action of AKR1C3 have been investigated by exploiting 6-Medroxyprogesterone acetate (MPA) an inhibitor of AKR1C ${ }^{32}$. In leukemic systems a synergistic effect on cell death occurs with the combination of MPA with PPARg ligand bezafibrate ${ }^{33}$. Combinatorial treatments of MPA and $\mathrm{PGD}_{2}$ have corroborated this 
in other cancer models to induce apoptosis and cell cycle arrest through PPARg driven activation pathways ${ }^{34}$, and other studies have echoed this approach in $\mathrm{CaP}^{35}$.

Therefore, the current study, examined the possibility that an AR-independent mechanism for AKR1C3 was operating in CaP cells and, in particular, we focused on a potential role in ADT-R $\mathrm{CaP}$ cells where AR signaling is either diminished or lost. By generating CaP cell lines stably expressing a short hairpin siRNA sequence to AKR1C3 we investigated responses to treatment with the PPARg ligand precursor and AKR1C3 substrate $\mathrm{PGD}_{2}$. 


\section{Materials \& Methods}

Ligands. Suberoylanilide hydroxamic acid (SAHA) (Merck Inc, New Jersey, USA), GW9662 (Sigma-Aldrich) and Prostaglandin $\mathrm{D}_{2}$ (Sigma-Aldrich) were stored in DMSO (Sigma-Aldrich) as $100 \mathrm{mM}$ stocks. Bezafibrate (PPARa/g), 6-medroxyprogesterone acetate (Sigma-Aldrich), and Indomethacin (Sigma-Aldrich) were stored as 10mM stocks in DMSO.

Cell Culture and shRNA Knockdown. ShRNA targeting AKR1C3 oligonucleotides containing the short hairpin sequence (Sigma-Aldrich) were annealed and inserted in a pcDNA3.1 vector (Invitrogen). Stably transfected cells were exposed to $100 \mathrm{mg} / \mathrm{ml}$ Neomycin sulphate (SigmaAldrich) as a selection agent. Human prostate cell lines used RWPE-1, LNCaP, PC-3, DU 145 were purchased from American Type Cell Culture (ATCC) Manassas, Virginia USA. RWPE-1 cells were maintained within Keratinocyte serum free medium (K-SFM) (Invitrogen GIBCO) used in combination with the recommended supplements of bovine pituitary extract $(0.05 \mathrm{mg} / \mathrm{ml})$ (BPE) and human recombinant epidermal growth factor $(5 \mathrm{ng} / \mathrm{ml})$ (EGF). LNCaP, PC-3 and DU 145 cells were maintained in RPMI 1640 medium (Sigma-Aldrich) containing 10\% fetal bovine serum (Invitrogen), 2mM L-Glutamine and containing 100 units $/ \mathrm{ml}$ Penicillin and $100 \mu \mathrm{g} / \mathrm{ml}$ Streptomycin. Cells were kept at $37^{\circ} \mathrm{C}$ in $95 \%$ air and $5 \% \mathrm{CO}_{2}$. Cells were washed in sterile phosphate buffered saline (PBS) and split using Trypsin-EDTA (Sigma-Aldrich) and seeded into new flasks containing fresh media. All experiments were conducted using cells between passages 15 and 28.

Primary prostate tumor material. All tumors were collected under IRB approval at Roswell Park Cancer Institute (RPCI), specifically the Genitourinary Disease Site Research Network at RPCI, which assesses applications for non-human subject research under guidance of the Office of Research Subject Protection. All patients at RPCI give written consent to allow tumor material not needed for pathological grading to be considered for non-human subject research. Total mRNA from local tumors and adjacent non-neoplastic tissue from the same patient were extracted from snap frozen radical prostatectomy samples with subsequent frozen section analysis for quality control. The frozen section H\&E was evaluated by a board certified pathologist for prostatic adenocarcinoma versus benign tissue. Segments of tissue corresponding to prostatic adenocarcinoma with equal to or greater than $70 \%$ neoplastic nuclei are submitted for RNA isolation. RNA processing was done in the Pathology Resource Network facilities with standard operating procedures as described previously ${ }^{36}$.

Proliferation assays. Proliferation (ViaLight HS, LumiTech, Nottingham, U.K.) was measured as described previously ${ }^{37}$ and optimized using different seeding densities to ensure exponential proliferation through the course of the experiment. Cancer cell lines $\left(2 \times 10^{3}\right.$ cells $/$ well $)$ and

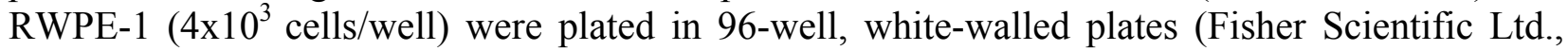
Loughborough, U.K.), dosed with agents to final volume of $100 \mu \mathrm{l} /$ well and incubated for 96hours, with re-dosing after 48hours. Cells were normalized to vehicle control treated wells performed in each separate assay plate. Each treatment was performed in technical triplicate and in biological triplicate experiments.

Q-RT-PCR. cDNA was prepared using random primers (Promega) and target genes relative expression quantitated using ABI 7500 - Applied Biosystems. Sequences for

AKR1C3 FORWARD GGGATCTCAACGAGACAAACG REVERSE AAAGGACTGGGTCCTCCAAGA PROBE TGGACCCGAACTCCCCCGGTG were designed and validated. 18S VIC-labeled probe was used as an endogenous control (Applied Biosystems). Measurements were carried in triplicate, in triplicate wells for each condition and ddCt fold changes calculated.

Multi-target micro-fluidic Q-RT-PCR $\mathbf{M}_{\mathbf{M}}$. Measurement of targeted multiple gene transcripts was undertaken on custom-designed TaqMan Low Density Array (ABI 7900HT Fast Real-Time PCR 
System) as described previously ${ }^{14}$ the full 95 gene list is available upon request. Briefly, the array included probes and primers for $18 \mathrm{~S}$ and the gene targets in nine functional groups whose expression together reflects nuclear receptor signaling capacity. These were 1. Nuclear receptors (e.g. high and broad affinity such as VDR and PPARs); 2. Nuclear receptor co-factors (e.g. coactivators [p160 family, non-p160 members, members of the 'bridging' DRIP/TRAP complex], co-repressors [NCOR1, NCOR2/SMRT, COPS2/TRIP15/Alien]; 3. Histone modifiers (histone deacetylases [e.g. HDACs hSIRT1] and acetyltransferases [P300, CBP, PCAF], histone methyltransferases [SUV39H1, SUV39H2], demethylases [KDM1A/LSD1], Histone deaminases [e.g. PAD14]); 4. Metabolic enzymes (e.g. CYP24 and SULTA1); 5. Cell death regulators (e.g. $C A S P 4$ and $B A X)$; 6. Transcription factors (e.g. $Y Y 1$ and $I D 1$ ); 7. Cell surface transporters (e.g. ABC transporters such as MRP3); 8. Cell cycle regulators (e.g. CCND1, GADD45a, CDKN1A, TP53); 9. Signal transduction (e.g. IGFBPs, MAPKs, CDH1). The exact choices represented in classes 1-3 were guided by SAGE expression data from normal prostate tissue ${ }^{38}$ and those in classes 4-9 included known direct target genes for nuclear receptors ${ }^{39-46}$. Total mRNA from cellcycle sorted cells was quantified in triplicate samples measured in duplicate as described previously ${ }^{14}$.

Fold changes were calculated for target gene expression and statistical analyses carried out using the TIGR MultiExperiment Viewer 4.0, MeV. A one sample t-test analysis based on permutation (Westfall Young stepdown ${ }^{47}$ - MaxT correction) was used to identify genes significantly expressed. In this case vectors containing gene expression values were tested against the mean of $18 \mathrm{~S}$ fold changes. One-Way ANOVA was used to identify genes that were differentially expressed for the shAKR1C3 PC-3 knock-down experiment compared to vector only PC-3 controls.

Western immunoblotting Total proteins were electrophoresed in a $12.5 \%$ gel, for 90 minutes at 120 volts. Proteins were then transferred onto PVDF (Polyvinylidene fluoride) membrane (45 minutes at 80 volts). The PVDF membranes were then left in 5\% non-fat milk diluted in Tribuffered saline containing 2\% Tween (TBS-T) detergent for 45 minutes. Monoclonal antiAKR1C3 antibody (Sigma-Aldrich) produced in mouse was diluted 1 in 10,000 into 5\% non-fat milk diluted in TBS-T. The PVDF membranes were left in the primary antibody mixture overnight in a cold room $\left(5^{\circ} \mathrm{C}\right)$ to prevent evaporation. The PVDF membranes were washed in TBS-T for 15 minutes changing the TBS-T every 5 minutes. Secondary HRP-labeled anti-mouse immunoglobulin was diluted 1 in 10,000 into TBS-T and the membranes incubated in the mixture for 45 minutes. Chemoluminescent ECL western blotting detection kit (Amersham, GE Health Care) was added in accordance with manufacturer's protocol.

Statistical analysis. Data shown are mean \pm SEM of at least three independent experiments with statistical significance defined as $\mathrm{P}<0.05 \quad(* \mathrm{P}<0.05 ; * * \mathrm{P}<0.01 ; * * * \mathrm{P}<0.001)$ using unpaired Students T-test and were conducted with Prism (GraphPad, CA). Statistical analysis on real-time PCR data was performed on mean det values. 


\section{$\underline{\text { Results }}$}

$A K R 1 C 3$ expression is elevated in prostate cancer cell lines and primary prostate cancer material. Figure 1A illustrates Q-RT-PCR data for $A K R I C 3$ in $\mathrm{CaP}$ cell lines, normalized to RWPE-1 non-malignant prostate cells. Significant elevation of $A K R I C 3$ was demonstrated in PC-3 and LNCaP cancer cell lines $(p<0.05)$; LNCaP (5.08 \pm 1.0 SEM), PC-3 $(7.54 \pm 0.1$ SEM). Figure 1B shows expression of $A K R 1 C 3, P P A R A$ and $P P A R G$ in thirteen human primary tumors compared to matched normal tissue, derived from radical prostatectomy. There was a significant increase in AKR1C3 levels (2.69 \pm 1.7 SEM). PPARA and PPARG levels were comparable between normal and tumor samples ${ }^{48}$.

Neither AKR1C3 inhibition nor knockdown enhances PPAR anti-proliferative signaling. Previously, studies of acute myeloid leukemia have shown combinatorial antitumor activity when AKR1C3 inhibitors are combined with Bezafibrate (a dual PPARa/g ligand). Assuming prostate cell lines have comparable basal turnover of cholesterol-derived prostaglandin substrate the similar response would be observed. However, the use of AKR1C3 inhibitors either indomethacin or 6-medroxyprogesterone acetate ${ }^{49}$ did not enhance the anti-proliferative effects of Bezafibrate against the non-malignant RWPE-1 cells or either $\mathrm{CaP}$ cell line (Figure 2A).

Stable transfection of short hairpin RNA targeted towards AKR1C3 in PC-3 and DU 145 resulted in significant reduction in both AKR1C3 mRNA (Figure 2B) and protein levels (Figure 2C). Cells were then treated with the PPARg agonist precursor $\mathrm{PGD}_{2}$ to examine the biological impact of AKR1C3 reduction. Figure 2D demonstrates reduction of AKR1C3 levels had no significant affect on proliferative response to $\mathrm{PGD}_{2}$ within PC-3 (Vector Only (VO) and shAKR1C3) and DU 145 (VO and shAKR1C3) cells. These data suggest that shAKR1C3 PC-3 and DU 145 cells have unchanged response to the PPARg ligand precursor $\mathrm{PGD}_{2}$.

Cell proliferation in response to SAHA in shAKR1C3 transfected cells. Explanations for deficiency of AKR1C3 inhibitor impact may involve FP1 receptor expression and inherent variations in export/import of prostaglandins. However, we reasoned that the lack of a response to AKR1C3 inhibitors maybe due to epigenetic blockade of PPARg transcriptional actions. Therefore, the HDAC inhibitor acid SAHA was used to treat AKR1C3 knockdown cells in an attempt to overcome epigenetic resistance at PPARg targets. Down regulation of AKR1C3 in DU 145 cells resulted in significant sensitization to the anti-proliferative actions of SAHA. (Figure 3 A and B). A similar trend was observed in PC-3 ShAKR1C3 cells although this did not reach significance when compared SAHA treated PC-3 VO cells (Figure $3 \mathrm{~A}$ and B). The lesser difference in PC-3 cells may relate the to greater sensitivity of PC-3 VO to SAHA treatment alone when compared to DU $145 \mathrm{VO}$ cells which displayed no antiproliferative response to SAHA. However, SAHA treatment did not sensitize shAKR1C3 cells to either the PPARg ligand precursor $\mathrm{PGD}_{2}$ or the direct PPARg ligand GW9662. Interestingly, DU 145 cells revealed a significantly increased sensitivity to $\mathrm{PGD}_{2}$ in shAKR1C3 cells. This reflects data on chemical inhibition of AKR1C3 by MPA leading to increased sensitivity to Bezafibrate (Figure 2A).

Multi-targeted micro-fluidic QT-RT-PCR of the NR network. The above findings in two prostate cancer cell line models suggest that the role of $\mathrm{AKR} 1 \mathrm{C} 3$ in $\mathrm{CaP}$ is different from that in leukemia and is only weakly linked to the protection of PPARg. To reveal the impact of reduced AKR1C3 levels in this priming event we examined expression of the NR network using a previously established microfluidic PCR approach ${ }^{8,14}$. We selected PC-3 cells for these experiments as arguably it arguably is a more relevant model of ADT-RCaP than DU 145 cells, as it in vivo it will metastasize to the same sites as observed in human disease $\mathrm{e}^{50}$. 
The most significantly deregulated genes in shAKR1C3 compared to VO PC-3 cells are shown in Figure 4. Interestingly, a common downregulation of a range of epigenetic regulators was observed, alongside AKR1C3 downregulation. These include HDACs, NR coactivators and NRs and PPARg coactivator (PPARGC1A). In addition the histone methyltransferase $S E T 7$ and proto-oncogene $M Y B$ were significantly down-regulated in shAKR1C3. The NFkB complex component IKBkB was the only gene to be significantly upregulated in the presence of shAKR1C3. Transcriptional activators forming the NFkB complex have been found to be important in prostate cancer progression and human prostate cancer prognosis ${ }^{51-53}$. This increase of NFKB in response to shAKR1C3 is of particular interest as it is a key driver of prostate cell proliferation and AKR1C3 presence influencing NFkB activity (through $\mathrm{PGF}_{2}$ production) has also been suggested by others ${ }^{54}$. 


\section{Discussion}

The current study was undertaken to investigate the roles of $\mathrm{AKR} 1 \mathrm{C} 3 \mathrm{in} \mathrm{CaP}$, as this enzyme is increasingly a focus in $\mathrm{CaP}$ research that includes its altered expression and function. The studies of others have focused on the role of this enzyme to alter ligand availability for steroidogenic androgen and estrogen receptors in the prostate. Additionally, studies and have considered the impact of $\mathrm{PGD}_{2}$ on cell proliferation in cells that over-express AKR1C3 ${ }^{55-59}$. By contrast, our previous studies show elevated AKR1C3 deprives AML cells of J-series prostaglandins that can act as endogenous PPAR ligands. Given that PPARg ligands have been investigated for the treatment of various cancer types for example neuroblastomas ${ }^{60}$, colorectal ${ }^{61}$, breast and prostate cancers ${ }^{62,63}$. It was hypothesized that the role in $\mathrm{CaP}$ for AKR1C3 may be to silence PPAR signaling. Furthermore, it has been demonstrated that stable expression of AKR1C3 in hormone dependent MCF-7 breast cancer cell lines negatively impacts anti-proliferative actions of $\mathrm{PGD}_{2}{ }^{27}$.

This study investigated AKR1C3 function by undertaking knock-down and chemical inhibition approaches in parallel to compare findings to previously published over-expression approaches 56,57 . In particular an overexpression investigation of AKR1C3 in PC-3 cells found overexpression promotes proliferation ${ }^{35}$. However, this study found $\mathrm{PGD}_{2}$ exposure to overexpressing AKR1C2 and AKR1C3 PC-3 models significantly reduces proliferation compared to controls. However, in this study reduction of AKR1C3 in the presence of $\mathrm{PGD}_{2}$ had no impact upon proliferation. This disparity reflects the unclear interplay between AKR1C2, AKR1C3 in prostaglandin metabolism.

PC-3 and DU 145 cells are derived from ADT-R CaP cells that are insensitive to AR signaling but retain the capacity for PPAR signaling. Therefore, knockdown of AKR1C3 in these models allows a clearer examination of the role of AKR1C3 in regulating PPARg. However, shAKR1C3 expression did not significantly alter responses to either endogenous $\left(\mathrm{PGD}_{2}\right)$ or synthetic PPARg (GW9662) ligands.

These data support the concept that either AKR1C3 is not a major regulator of PPARg in prostate cells or that in $\mathrm{CaP}$ the ability of AKR1C3 to exert such an action is overridden by epigenetic events ${ }^{36,37,64}$. Therefore SAHA was utilized in an attempt to restore PPARg function. Interestingly, the shAKR1C3 clones of DU 145 were significantly more sensitive to SAHA than controls; in PC-3 cells this was smaller and non-significant but trending in the same direction. This supports a hitherto unsuspected link between AKR1C3 actions and the epigenome. The anti-proliferative effects of combining AKR1C3 knockdown and SAHA treatment were not further enhanced in the presence of $\mathrm{PGD}_{2}$, reinforcing the notion that these epigenetic actions of AKR1C3 in CaP cells are independent of PPARs. It is however, possible alternative routes of 15 delta- $\mathrm{PGJ}_{2}$ elimination in particular, conjugation and dismissal by glutathione could play a contributory role in the absence of $\mathrm{PGD}_{2}$ response.

The fact that reduction of AKR1C3 levels lead to increased sensitivity towards SAHA suggested that $\mathrm{AKR} 1 \mathrm{C} 3$ has a role in promoting $\mathrm{CaP}$ survival, proliferation and its removal whilst not directly affecting cell growth primes cells for sensitivity to other potential $\mathrm{CaP}$ therapeutics. This suggests overexpression of AKR1C3 has an impact upon the epigenetic state of the cell, and is independent of both PPAR and AR signaling, (given the diminished/absent AR state of these cells). The down regulation of a number of HDACs following AKR1C3 knockdown supports the hypothesis that AKR1C3 in some manner is able to regulate enzymes governing epigenetic gene regulation, explaining why the cells gain sensitivity to SAHA. Interestingly, the upregulation of IKBkB correlates with previous findings suggesting a link between AKR1C3 and NFkB signaling pathways ${ }^{65,66}$. More broadly to establish the association of AKR1C3 with tumor status The Cancer Genome Atlas 
(TCGA) data was examined to identify genes associated with AKR1C3 signalling, and in parallel the AR and PPARg signalling. The goal was to reveal commonly distorted components and to infer how AKR1C3 may be co-expressed with either of these pathways, and at what stage of prostate cancer. We mined RNA-Seq associated with AKR1C3 in two different cohorts of prostate cancer samples in TCGA, namely, the University of Michigan cohort of 94 advanced stage and invasive tumors ${ }^{67}$ and the Stand Up to Cancer (SU2C) cohort of 118 metastatic castrate recurrent tumors ${ }^{68}$. From these analyses we generated heatmaps for each of the tumor cohort (Supplementary Figure 1). In each case AKR1C3 (red arrowhead) grouped by expression in a different cluster than the AR (Black arrowhead). In particular AKR1C3 expression clusters more closely with PPARs than the AR. These findings suggest that taking an unbiased approach to the networks in which AKR1C3 is implicated supports a role of close association with PPARs rather than the AR and this is especially evident in aggressive and advanced disease that has failed anti-androgen treatment.

Furthermore in the SU2C cohort of 114 tumors, AKR1C3 is over-expressed and amplified in $4 \%$ of tumors. However network analyses ${ }^{69}$ of AKR1C3 reveals a direct protein-protein interaction with ZHX1 which is a corepressor and known to recruit $\mathrm{HDACs}^{70}$. ZHX1 ${ }^{71}$ is a relatively unexplored protein. Large-scale protein-protein screens reveal that it interacts with proteins including histone deacetylase (HDAC1), the DNA methyltransferases (DNMT1 and DNMT3B $)^{72}$, and a number of transcription factors (NFYa and b) ${ }^{73}$. These findings generate confidence that a ZHX1 complex initiates chromatin condensation and leads to gene silencing. Together we believe strongly that our data generated by two different experimental approaches, and these parallel findings from others indicate a direct and functional link between AKR1C3 and the regulation of the epigenome.

The current study has revealed a novel role of AKR1C3 expression on the epigenetic status of prostate cancer cells that is independent of AR and PPARs signaling and highlights the potential for selective inhibitors of AKRIC3 in combination with SAHA or other HDAC inhibitors as prospective therapy in AR resistant disease (Figure 5). 


\section{Acknowledgements}

MJC acknowledges support in part from National Institute of Health grants [R01 CA09536706 and 2R01-CA-095045-06] and the Prostate program of the Department of Defense Congressionally Directed Medical Research Programs [W81XWH-14-1-0608], MJC also acknowledges support, in part, of the NCI Cancer Center Support Grant to the Roswell Park Cancer Institute [CA016056]. SB acknowledges support in part from the Prostate program of the Department of Defense Congressionally Directed Medical Research Programs [W81XWH-13-1-0276; PC121785].

\section{Author Contributions}

CLD, SB and FK conducted the work. MJC and CLD wrote the manuscript. MJC and CMB conceived and designed the research. 


\section{References}

1 Rosenfeld, M. G., Lunyak, V. V. \& Glass, C. K. Sensors and signals: a coactivator/corepressor/epigenetic code for integrating signal-dependent programs of transcriptional response. Genes Dev. 20, 1405-1428 (2006).

2 Perissi, V., Jepsen, K., Glass, C. K. \& Rosenfeld, M. G. Deconstructing repression: evolving models of co-repressor action. Nat Rev Genet 11, 109-123, doi:nrg2736 [pii]10.1038/nrg2736.

3 Chomienne, C., Fenaux, P. \& Degos, L. Retinoid differentiation therapy in promyelocytic leukemia. FASEB journal : official publication of the Federation of American Societies for Experimental Biology 10, 1025-1030 (1996).

4 Thorne, J. \& Campbell, M. J. The vitamin D receptor in cancer. The Proceedings of the Nutrition Society 67, 115-127, doi:10.1017/S0029665108006964 (2008).

5 Campbell, M. J., Carlberg, C. \& Koeffler, H. P. A Role for the PPARgamma in Cancer Therapy. PPAR research 2008, 314974, doi:10.1155/2008/314974 (2008).

6 Mueller, E. et al. Effects of ligand activation of peroxisome proliferator-activated receptor gamma in human prostate cancer. Proceedings of the National Academy of Sciences of the United States of America 97, 10990-10995, doi:10.1073/pnas.180329197 (2000).

7 Newling, D. et al. Assessment of hormone refractory prostate cancer. Urology 49, 4653 (1997).

8 Battaglia, S. et al. Elevated NCOR1 disrupts PPAR \{alpha\}/\{gamma\} signaling in prostate cancer and forms a targetable epigenetic lesion. Carcinogenesis, doi:bgq086 [pii]10.1093/carcin/bgq086 (2010).

9 Liao, G. et al. Regulation of androgen receptor activity by the nuclear receptor corepressor SMRT. The Journal of biological chemistry 278, 5052-5061, doi:10.1074/jbc.M206374200M206374200 [pii] (2003).

10 Hodgson, M. C. et al. The androgen receptor recruits nuclear receptor CoRepressor $(\mathrm{N}-\mathrm{CoR})$ in the presence of mifepristone via its $\mathrm{N}$ and $\mathrm{C}$ termini revealing a novel molecular mechanism for androgen receptor antagonists. The Journal of biological chemistry 280, 6511-6519, doi:M408972200 [pii]10.1074/jbc.M408972200 (2005).

11 Battaglia, S., Maguire, O. \& Campbell, M. J. Transcription factor co-repressors in cancer biology: roles and targeting. International journal of cancer. Journal international du cancer 126, 2511-2519, doi:10.1002/ijc.25181 (2010).

12 Chang, T. H. \& Szabo, E. Enhanced growth inhibition by combination differentiation therapy with ligands of peroxisome proliferator-activated receptor-gamma and inhibitors of histone deacetylase in adenocarcinoma of the lung. Clin.Cancer Res. 8, 1206-1212 (2002).

13 Battaglia, S. et al. Elevated NCOR1 disrupts PPAR signaling in prostate cancer and forms a targetable epigenetic lesion. Carcinogenesis (2010).

14 Abedin, S. A. et al. Elevated NCOR1 disrupts a network of dietary-sensing nuclear receptors in bladder cancer cells. Carcinogenesis 30, 449-456, doi:10.1093/carcin/bgp005 (2009).

$15 \mathrm{Wu}, \mathrm{C}$. H. et al. Clinical implications of aldo-keto reductase family 1 member $\mathrm{C} 3$ and its relationship with lipocalin 2 in cancer of the uterine cervix. Gynecologic oncology 132, 474-482, doi:10.1016/j.ygyno.2013.11.032 (2014).

16 Penning, T. M. et al. Human 3alpha-hydroxysteroid dehydrogenase isoforms (AKR1C1-AKR1C4) of the aldo-keto reductase superfamily: functional plasticity and 
tissue distribution reveals roles in the inactivation and formation of male and female sex hormones. The Biochemical journal 351, 67-77 (2000).

17 Knuuttila, M. et al. Castration induces up-regulation of intratumoral androgen biosynthesis and androgen receptor expression in an orthotopic $\mathrm{VCaP}$ human prostate cancer xenograft model. The American journal of pathology 184, 2163-2173, doi:10.1016/j.ajpath.2014.04.010 (2014).

18 Kikuchi, A. et al. In vitro and in vivo characterisation of ASP9521: a novel, selective, orally bioavailable inhibitor of 17beta-hydroxysteroid dehydrogenase type 5 (17betaHSD5; AKR1C3). Investigational new drugs 32, 860-870, doi:10.1007/s10637-014-0130-5 (2014).

19 Fankhauser, M. et al. Canonical androstenedione reduction is the predominant source of signaling androgens in hormone-refractory prostate cancer. Clinical cancer research : an official journal of the American Association for Cancer Research 20, 5547-5557, doi:10.1158/1078-0432.CCR-13-3483 (2014).

20 Tian, Y. et al. AKR1C3 overexpression may serve as a promising biomarker for prostate cancer progression. Diagnostic pathology 9, 42, doi:10.1186/1746-1596-9-42 (2014).

21 Yepuru, M. et al. Steroidogenic enzyme AKR1C3 is a novel androgen receptorselective coactivator that promotes prostate cancer growth. Clinical cancer research: an official journal of the American Association for Cancer Research 19, 5613-5625, doi:10.1158/1078-0432.CCR-13-1151 (2013).

22 Hofman, J., Malcekova, B., Skarka, A., Novotna, E. \& Wsol, V. Anthracycline resistance mediated by reductive metabolism in cancer cells: the role of aldo-keto reductase 1C3. Toxicology and applied pharmacology 278, 238-248, doi:10.1016/j.taap.2014.04.027 (2014).

23 Segawa, Y. et al. Expression of peroxisome proliferator-activated receptor (PPAR) in human prostate cancer. The Prostate 51, 108-116 (2002).

24 Mitsiades, N. et al. Distinct patterns of dysregulated expression of enzymes involved in androgen synthesis and metabolism in metastatic prostate cancer tumors. Cancer research 72, 6142-6152, doi:10.1158/0008-5472.CAN-12-1335 (2012).

25 Bauman, D. R., Steckelbroeck, S., Peehl, D. M. \& Penning, T. M. Transcript profiling of the androgen signal in normal prostate, benign prostatic hyperplasia, and prostate cancer. Endocrinology 147, 5806-5816, doi:10.1210/en.2006-0627 (2006).

26 Wako, K. et al. Expression of androgen receptor through androgen-converting enzymes is associated with biological aggressiveness in prostate cancer. Journal of clinical pathology 61, 448-454, doi:10.1136/jcp.2007.050906 (2008).

27 Byrns, M. C., Duan, L., Lee, S. H., Blair, I. A. \& Penning, T. M. Aldo-keto reductase $1 \mathrm{C} 3$ expression in MCF-7 cells reveals roles in steroid hormone and prostaglandin metabolism that may explain its over-expression in breast cancer. The Journal of steroid biochemistry and molecular biology 118, 177-187, doi:10.1016/j.jsbmb.2009.12.009 (2010).

28 Yin, Y. D. et al. The Activity of SN33638, an Inhibitor of AKR1C3, on Testosterone and 17beta-Estradiol Production and Function in Castration-Resistant Prostate Cancer and ER-Positive Breast Cancer. Frontiers in oncology 4, 159, doi:10.3389/fonc.2014.00159 (2014).

29 Smuc, T. \& Rizner, T. L. Expression of 17beta-hydroxysteroid dehydrogenases and other estrogen-metabolizing enzymes in different cancer cell lines. Chem Biol Interact 178, 228-233, doi:S0009-2797(08)00548-6 [pii]10.1016/j.cbi.2008.10.038 (2009). 
30 Forman, B. M. et al. 15-Deoxy-delta 12, 14-prostaglandin J2 is a ligand for the adipocyte determination factor PPAR gamma. Cell 83, 803-812 (1995).

31 Kliewer, S. A. et al. A prostaglandin J2 metabolite binds peroxisome proliferatoractivated receptor gamma and promotes adipocyte differentiation. Cell 83, 813-819 (1995).

32 Penning, T. M., Sharp, R. B. \& Krieger, N. R. Purification and properties of 3 alphahydroxysteroid dehydrogenase from rat brain cytosol. Inhibition by nonsteroidal antiinflammatory drugs and progestins. J Biol Chem 260, 15266-15272 (1985).

33 Khanim, F. L. et al. Combined bezafibrate and medroxyprogesterone acetate: potential novel therapy for acute myeloid leukaemia. PloS one 4, e8147, doi:10.1371/journal.pone.0008147 (2009).

34 Desmond, J. C. et al. The aldo-keto reductase AKR1C3 is a novel suppressor of cell differentiation that provides a plausible target for the non-cyclooxygenase-dependent antineoplastic actions of nonsteroidal anti-inflammatory drugs. Cancer research $\mathbf{6 3}$, 505-512 (2003).

35 Wang, S., Yang, Q., Fung, K. M. \& Lin, H. K. AKR1C2 and AKR1C3 mediated prostaglandin D2 metabolism augments the PI3K/Akt proliferative signaling pathway in human prostate cancer cells. Molecular and cellular endocrinology 289, 60-66, doi:10.1016/j.mce.2008.04.004 (2008).

36 Battaglia, S. et al. Elevated NCOR1 disrupts PPARalpha/gamma signaling in prostate cancer and forms a targetable epigenetic lesion. Carcinogenesis 31, 1650-1660, doi:10.1093/carcin/bgq086 (2010).

37 Khanim, F. L. et al. Altered SMRT levels disrupt vitamin D3 receptor signalling in prostate cancer cells. Oncogene 23, 6712-6725, doi:10.1038/sj.onc.12077721207772 [pii] (2004).

38 Lal, A. et al. A public database for gene expression in human cancers. Cancer Res. 59, 5403-5407 (1999).

39 Zandbergen, F. et al. The G0/G1 switch gene 2 is a novel PPAR target gene. Biochem.J. 392, 313-324 (2005).

40 Matilainen, M., Malinen, M., Saavalainen, K. \& Carlberg, C. Regulation of multiple insulin-like growth factor binding protein genes by 1alpha,25-dihydroxyvitamin D3. Nucleic Acids Res. 33, 5521-5532 (2005).

41 Towsend, K. et al. Identification of VDR-responsive gene signatures in breast cancer cells. Oncology 71, 111-123, doi:000100989 [pii]10.1159/000100989 (2006).

42 Degenhardt, T., Matilainen, M., Herzig, K. H., Dunlop, T. W. \& Carlberg, C. The insulin-like growth factor binding protein 1 gene is a primary target of peroxisome proliferator-activated receptors. J.Biol.Chem. (2006).

43 Chene, G. et al. n-3 and n-6 polyunsaturated fatty acids induce the expression of COX-2 via PPARgamma activation in human keratinocyte HaCaT cells. Biochim Biophys Acta 1771, 576-589, doi:S1388-1981(07)00039-X [pii]10.1016/j.bbalip.2007.02.014 (2007).

44 Janabi, N. Selective inhibition of cyclooxygenase-2 expression by 15-deoxyDelta(12,14)(12,14)-prostaglandin $\mathrm{J}(2)$ in activated human astrocytes, but not in human brain macrophages. J Immunol 168, 4747-4755 (2002).

45 Seuter, S., Vaisanen, S., Radmark, O., Carlberg, C. \& Steinhilber, D. Functional characterization of vitamin D responding regions in the human 5-Lipoxygenase gene. Biochim.Biophys.Acta (2007). 
46 Campbell, M. J., Elstner, E., Holden, S., Uskokovic, M. \& Koeffler, H. P. Inhibition of proliferation of prostate cancer cells by a 19-nor-hexafluoride vitamin D3 analogue involves the induction of p21waf1, p27kip1 and E-cadherin. Journal of molecular endocrinology 19, 15-27 (1997).

47 Qiu, X., Xiao, Y., Gordon, A. \& Yakovlev, A. Assessing stability of gene selection in microarray data analysis. BMC Bioinformatics 7, 50, doi:1471-2105-7-50 [pii]10.1186/1471-2105-7-50 (2006).

48 Fung, K. M. et al. Increased expression of type 2 3alpha-hydroxysteroid dehydrogenase/type 5 17beta-hydroxysteroid dehydrogenase (AKR1C3) and its relationship with androgen receptor in prostate carcinoma. Endocr.Relat Cancer 13, 169-180 (2006).

49 Lovering, A. L. et al. Crystal structures of prostaglandin $\mathrm{D}(2)$ 11-ketoreductase (AKR1C3) in complex with the nonsteroidal anti-inflammatory drugs flufenamic acid and indomethacin. Cancer Res. 64, 1802-1810 (2004).

50 Virtanen, S. S., Vaananen, H. K., Harkonen, P. L. \& Lakkakorpi, P. T. Alendronate inhibits invasion of PC-3 prostate cancer cells by affecting the mevalonate pathway. Cancer Res 62, 2708-2714 (2002).

51 Jin, R. et al. Activation of NF-kappa B signaling promotes growth of prostate cancer cells in bone. PloS one 8, e60983, doi:10.1371/journal.pone.0060983 (2013).

52 Jin, R. et al. NF-kappaB gene signature predicts prostate cancer progression. Cancer research 74, 2763-2772, doi:10.1158/0008-5472.CAN-13-2543 (2014).

53 Chen, C. D. \& Sawyers, C. L. NF-kappa B activates prostate-specific antigen expression and is upregulated in androgen-independent prostate cancer. Molecular and cellular biology 22, 2862-2870 (2002).

54 Penning, T. M. \& Byrns, M. C. Steroid hormone transforming aldo-keto reductases and cancer. Annals of the New York Academy of Sciences 1155, 33-42, doi:10.1111/j.1749-6632.2009.03700.x (2009).

55 Schulze, J. J., Karypidis, H. \& Ekstrom, L. Basal and Regulatory Promoter Studies of the AKR1C3 Gene in Relation to Prostate Cancer. Frontiers in pharmacology 3, 151, doi:10.3389/fphar.2012.00151 (2012).

56 Chen, M. et al. Crystal structures of AKR1C3 containing an N-(aryl)amino-benzoate inhibitor and a bifunctional AKR1C3 inhibitor and androgen receptor antagonist. Therapeutic leads for castrate resistant prostate cancer. Bioorganic \& medicinal chemistry letters 22, 3492-3497, doi:10.1016/j.bmcl.2012.03.085 (2012).

57 Dozmorov, M. G. et al. Elevated AKR1C3 expression promotes prostate cancer cell survival and prostate cell-mediated endothelial cell tube formation: implications for prostate cancer progression. BMC cancer 10, 672, doi:10.1186/1471-2407-10-672 (2010).

58 Wang, S., Yang, Q., Fung, K. M. \& Lin, H. K. AKR1C2 and AKR1C3 mediated prostaglandin D2 metabolism augments the PI3K/Akt proliferative signaling pathway in human prostate cancer cells. Molecular and cellular endocrinology 289, 60-66, doi:10.1016/j.mce.2008.04.004 (2008).

59 Fung, K. M. et al. Increased expression of type 2 3alpha-hydroxysteroid dehydrogenase/type 5 17beta-hydroxysteroid dehydrogenase (AKR1C3) and its relationship with androgen receptor in prostate carcinoma. Endocrine-related cancer 13, 169-180, doi:10.1677/erc.1.01048 (2006).

$60 \mathrm{Wu}, \mathrm{J} . \mathrm{S}$. et al. Ligand-activated peroxisome proliferator-activated receptor-gamma protects against ischemic cerebral infarction and neuronal apoptosis by 14-3-3 epsilon 
upregulation. Circulation 119, 1124-1134, doi:CIRCULATIONAHA.108.812537 [pii]10.1161/CIRCULATIONAHA.108.812537 (2009).

61 Girnun, G. PPARG: a new independent marker for colorectal cancer survival. Gastroenterology 136, 1157-1160, doi:S0016-5085(09)00202-9 [pii]10.1053/j.gastro.2009.02.022 (2009).

62 Bonofiglio, D. et al. Peroxisome proliferator-activated receptor gamma activates fas ligand gene promoter inducing apoptosis in human breast cancer cells. Breast Cancer Res Treat 113, 423-434, doi:10.1007/s10549-008-9944-1 (2009).

63 Nagata, D. et al. Peroxisome proliferator-activated receptor-gamma and growth inhibition by its ligands in prostate cancer. Cancer Detect Prev 32, 259-266, doi:S0361-090X(08)00072-X [pii]10.1016/j.cdp.2008.05.008 (2008).

64 Battaglia, S., Maguire, O. \& Campbell, M. J. Transcription factor co-repressors in cancer biology: roles and targeting. International journal of cancer. Journal international du cancer 126, 2511-2519, doi:10.1002/ijc.25181 (2010).

65 Mantel, A. et al. Aldo-keto reductase 1C3 is expressed in differentiated human epidermis, affects keratinocyte differentiation, and is upregulated in atopic dermatitis. The Journal of investigative dermatology 132, 1103-1110, doi:10.1038/jid.2011.412 (2012).

66 Straus, D. S. et al. 15-deoxy-delta 12,14-prostaglandin J2 inhibits multiple steps in the NF-kappa B signaling pathway. Proceedings of the National Academy of Sciences of the United States of America 97, 4844-4849 (2000).

67 Grasso, C. S. et al. The mutational landscape of lethal castration-resistant prostate cancer. Nature 487, 239-243, doi:10.1038/nature11125 (2012).

68 Robinson, D. et al. Integrative clinical genomics of advanced prostate cancer. Cell 161, 1215-1228, doi:10.1016/j.cell.2015.05.001 (2015).

69 Keshava Prasad, T. S. et al. Human Protein Reference Database--2009 update. Nucleic acids research 37, D767-772, doi:10.1093/nar/gkn892 (2009).

70 Stelzl, U. et al. A human protein-protein interaction network: a resource for annotating the proteome. Cell 122, 957-968, doi:10.1016/j.cell.2005.08.029 (2005).

71 Yamada, K., Printz, R. L., Osawa, H. \& Granner, D. K. Human ZHX1: cloning, chromosomal location, and interaction with transcription factor NF-Y. Biochemical and biophysical research communications 261, 614-621, doi:10.1006/bbrc.1999.1087 (1999).

72 Kim, S. H. et al. Zinc-fingers and homeoboxes 1 (ZHX1) binds DNA methyltransferase (DNMT) 3B to enhance DNMT3B-mediated transcriptional repression. Biochem Biophys Res Commun 355, 318-323, doi:10.1016/j.bbrc.2007.01.187 (2007).

73 Yamada, K., Osawa, H. \& Granner, D. K. Identification of proteins that interact with NF-YA. FEBS letters 460, 41-45 (1999). 
Figure 1. (A) AKR1C3 is elevated in most but not all prostate cancer cell lines and tissue samples. Total RNA from RWPE-1, LNCaP, PC-3 and DU 145 cells was extracted and reverse transcribed. Levels of $A K R I C 3$ mRNA were measured using Q-RT-PCR using ribosomal $18 \mathrm{~S}$ as an endogenous control. Values were normalized relative to the nonmalignant immortalized prostate RWPE-1 cell line shown as fold change in AKRIC3. Bars indicate mean values \pm SEM of at least three independent biological measurements performed in triplicate PCR wells. (B) AKR1C3 is elevated in most human prostate cancer tissue samples. Thirteen samples of human prostate tumors were used and total mRNA extracted and subject to reverse transcription. The Q-RT-PCR was performed on the resulting cDNA using $18 \mathrm{~S}$ as an endogenous control. The ddCt values for non-tumorigenic tissue samples were normalized and compared to human tumor samples. Statistical analysis was performed using t-test. $*=$ p-value $0.05, * *=$ p-value $0.01, * * *=$-value 0.001 .

Figure 2. Reducing AKR1C3 levels is unable to restore anti-proliferative PGD $_{2}$ response. (A) RWPE-1, PC-3 and DU 145 cells were plated out at $2 \times 10^{3}$ cells per well with bezafibrate $(0.1 \mathrm{M})$ alone or in combination with indomethacin $(20 \mathrm{M})$ or MPA $(0.5 \mathrm{M})$. After incubation for 48 hours the cells were re-dosed again. Total treatment time was 96 hours. Bars indicate the mean of at least three independent experiments \pm SEM. (B) PC-3 and DU 145 shAKR1C3 cells show significant reduction in AKRIC3 mRNA and protein in comparison to vector only. Q-RT-PCR was performed on the resulting cDNA using $18 \mathrm{~S}$ as an endogenous control. (C) DU 145 shows Western immunobloting analysis of shAKR1C3 transfected cells and vector only cells probed with AKR1C3 specific antibody and detected using chemoluminesence. Image shown is representative of three independent experiments.

(D) Cells were plated out at $2 \times 10^{3}$ cells per well with $\mathrm{PGD}_{2}$ added $(0.62 \mathrm{M}, 1.25 \mathrm{M}, 2.5 \mathrm{M}$, or $5.0 \mathrm{M}$ ) and after incubation for 48 hours the cells were re-dosed with $\mathrm{PGD}_{2}$. Total treatment time was 96 hours. Each data point represents the mean of four experiments each in triplicate wells \pm SEM. Statistical analysis was performed using t-test $*=\mathrm{p}$-value $0.05, * *=\mathrm{p}$-value $0.01, * * *=$ p-value 0.001 .

Figure 3. The HDAC inhibitor SAHA shows no interaction with PPARg mediated signaling. (A) PC-3 and DU 145 cells were plated out at $2 \times 10^{3}$ cells per well with $\mathrm{PGD}_{2}$ $(2.5 \mathrm{M})$ alone or in combination with SAHA $(0.5 \mathrm{M})$. After incubation for 48 hours the cells were re-dosed again. Total treatment time was 96 hours. Bars indicate the mean of at least three independent experiments \pm SEM. Statistical analysis was performed using t-test $*=\mathrm{p}$ value $0.05, * *=\mathrm{p}$-value $0.01, * * *=\mathrm{p}$-value 0.001 . (B) PC-3 and DU 145 cells were plated out at $2 \times 10^{3}$ cells per well with GW9662 $(1.0 \mathrm{M})$ alone or in combination with SAHA $(0.5 \mathrm{M})$, after incubation for 48 hours the cells were re-dosed again. Total treatment time was 96 hours. Bars indicate the mean of at least three independent experiments \pm SEM. Statistical analysis was performed using t-test $*=\mathrm{p}$-value $0.05, * *=\mathrm{p}$-value $0.01, * * *=\mathrm{p}$-value 0.001 .

Figure 4. AKR1C3 knockdown influences a network of genes involved in transcriptional regulation. Basal PC-3 vector only controls and shAKR1C3 PC-3 samples were used. Total mRNA was collected and added to a micro-fluidic reverse transcription Q-RT-PCR two step reaction. Primer sets on the card were selected for their nuclear receptor prostate specific context consisting of nine groups listed in the materials and methods section.

Figure 5. A model of AKR1C3 mediated epigenetic resistance in prostate cancer. (a) $\mathrm{PGD}_{2}$ is responsible for the generation of PPARg ligand $\mathrm{PGJ}_{2}$. (b) Increased AKR1C3 levels divert $\mathrm{PGD}_{2}$ converting it to $11 \mathrm{~b}-\mathrm{PGF}_{2}$ contributing to the activation of proliferative transcription factors such as the NFkB complex. (c) Observations in shAKR1C3 prostate cancer cells suggest AKR1C3 plays a role in sustained repression of anti-proliferative genes, 
this can be relieved with impairment of AKR1C3 activity combined with the treatment of HDAC inhibitor permitting access to the HATs responsible for permissive gene activation. 
A $* * *$

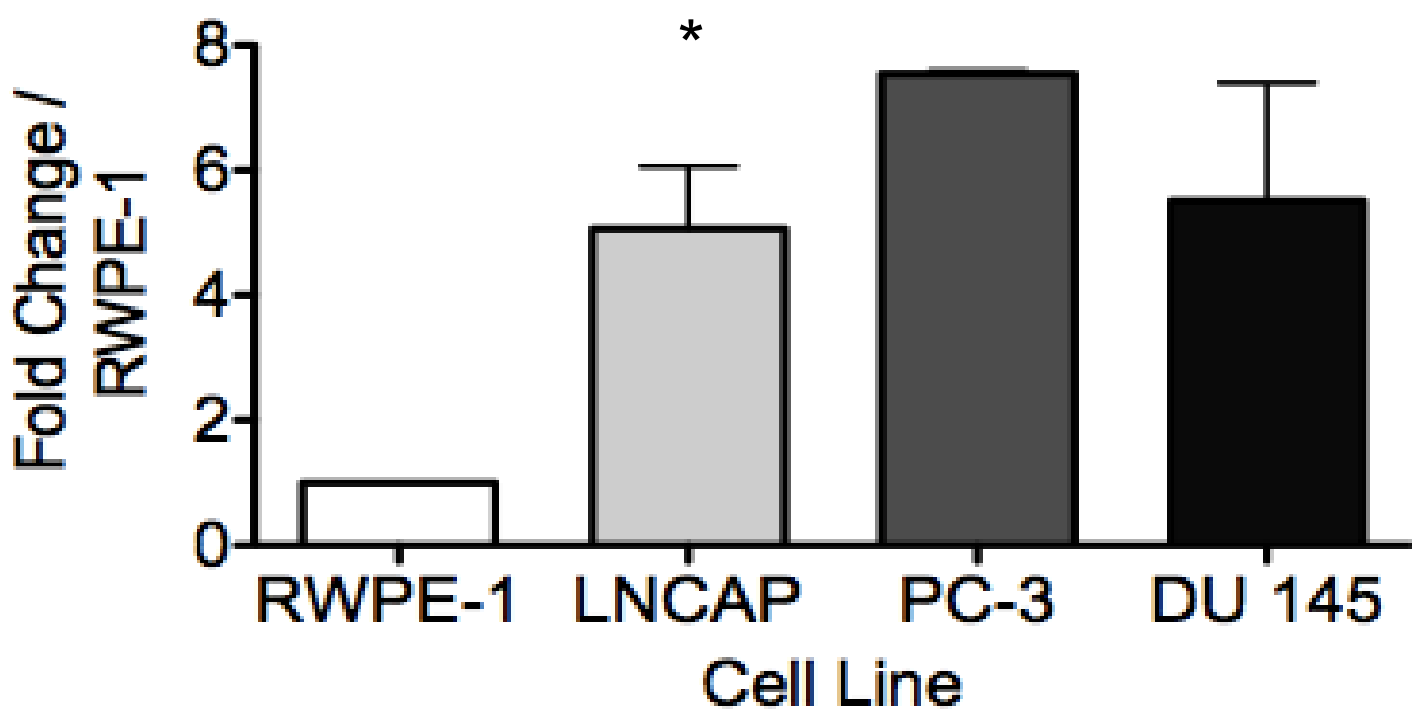

B **

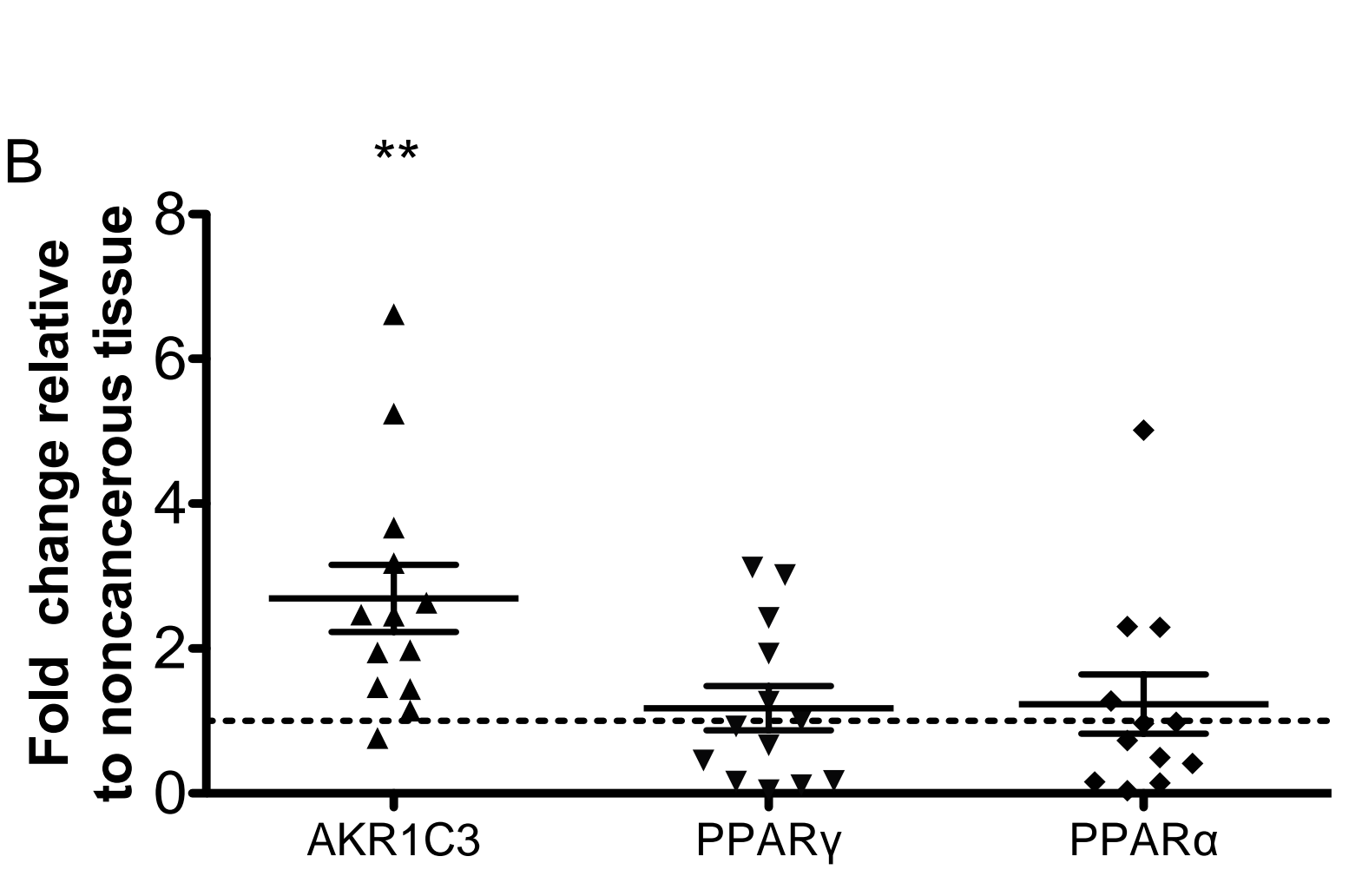

Figure 1

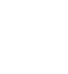

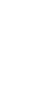

\section{Cell Line}
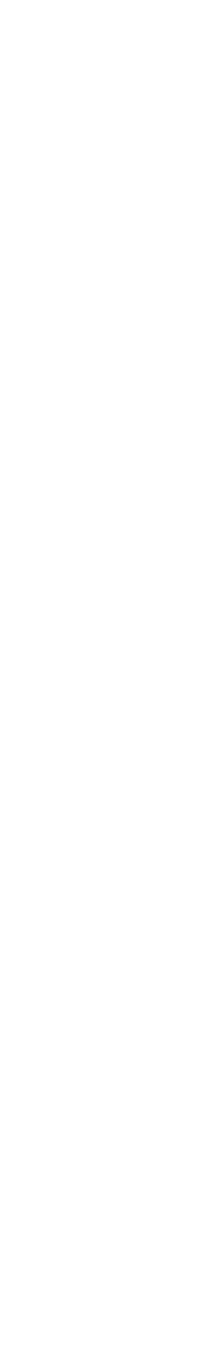

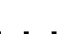

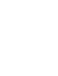


A

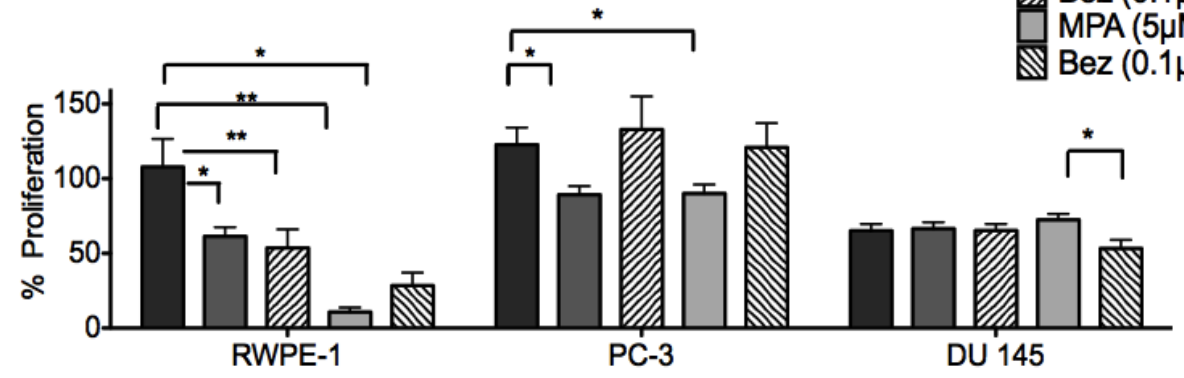

B
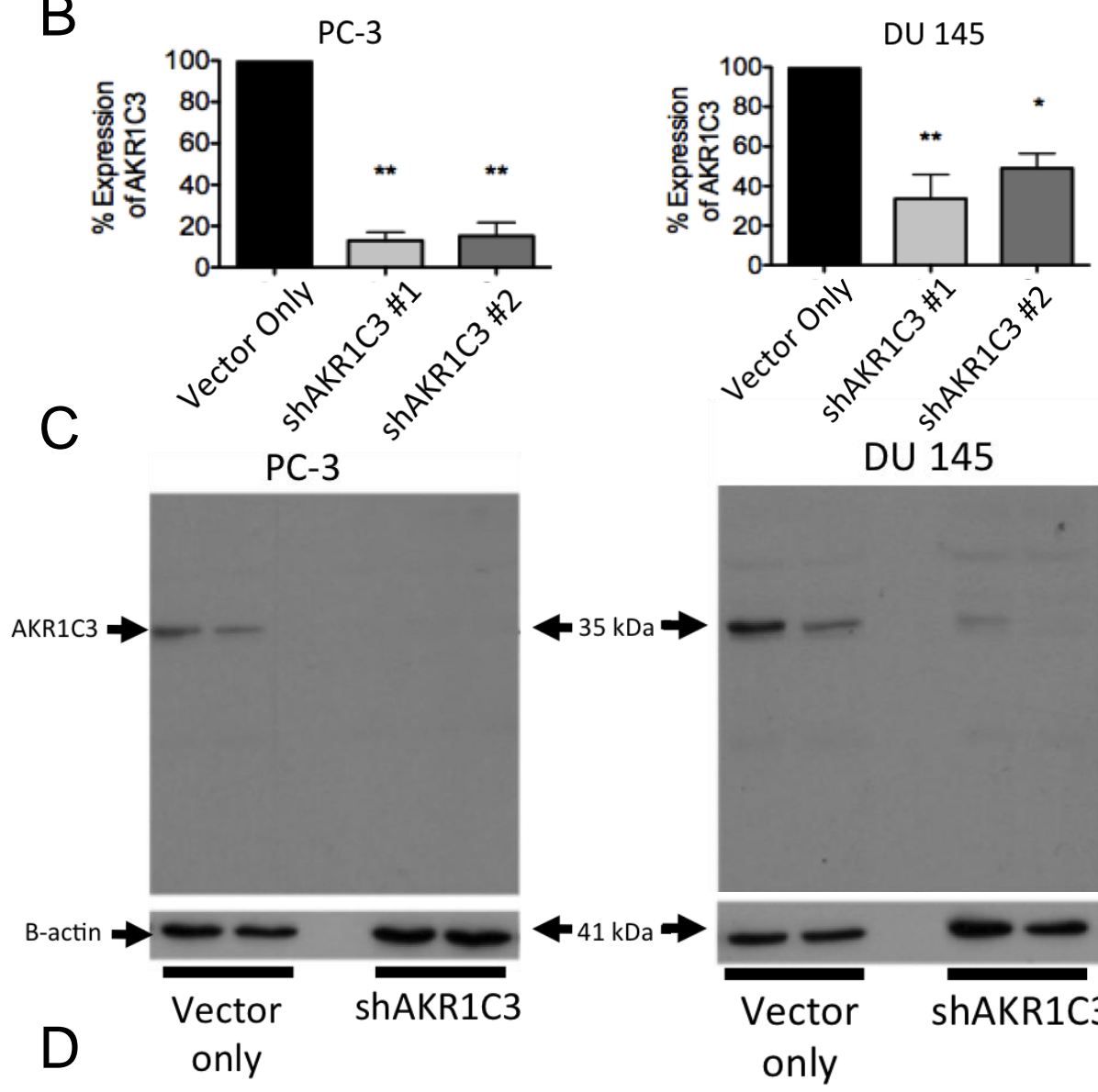

- PC-3 VO -- PC-3 shAKR1C3
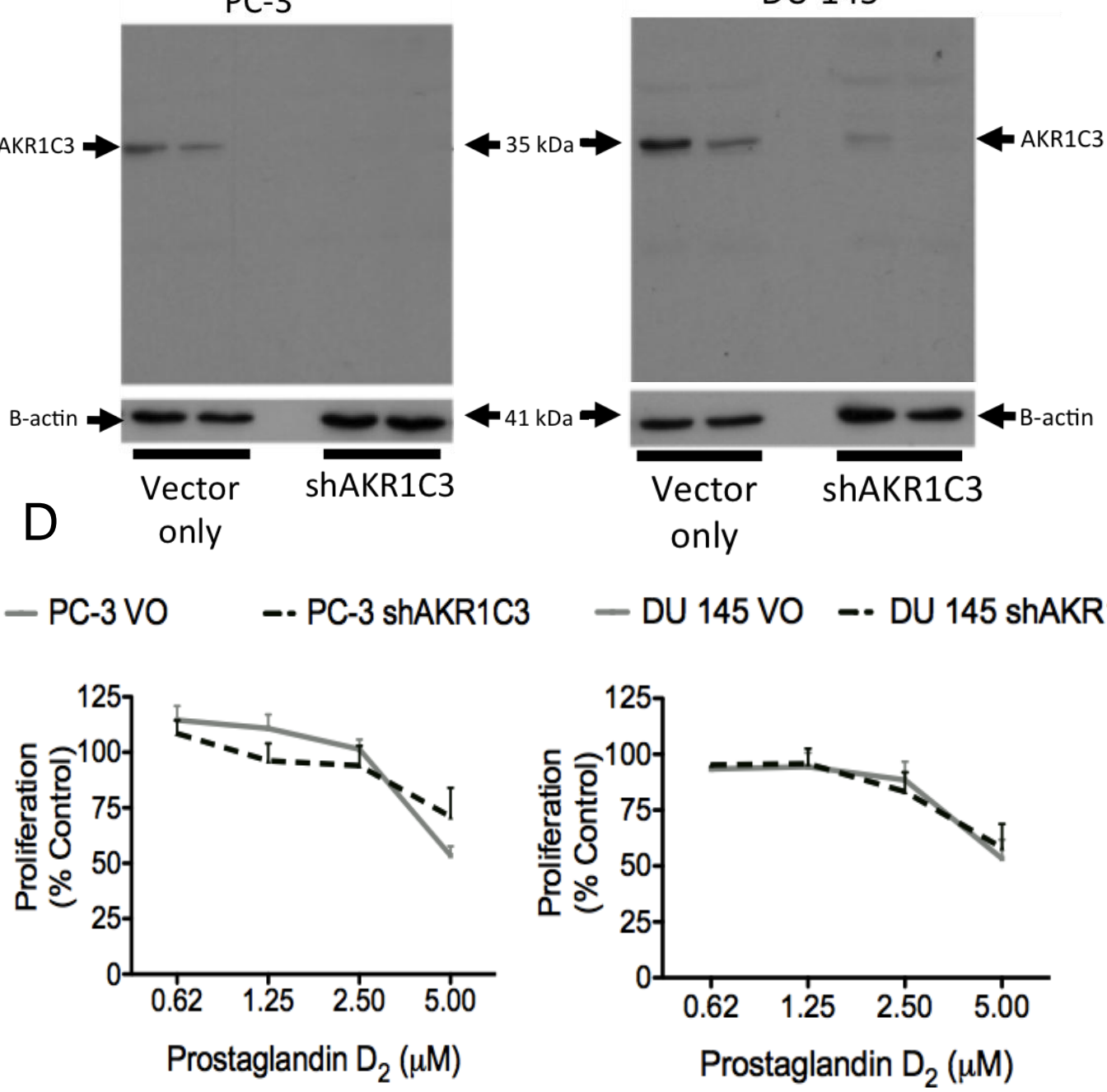

Figure 2 
A

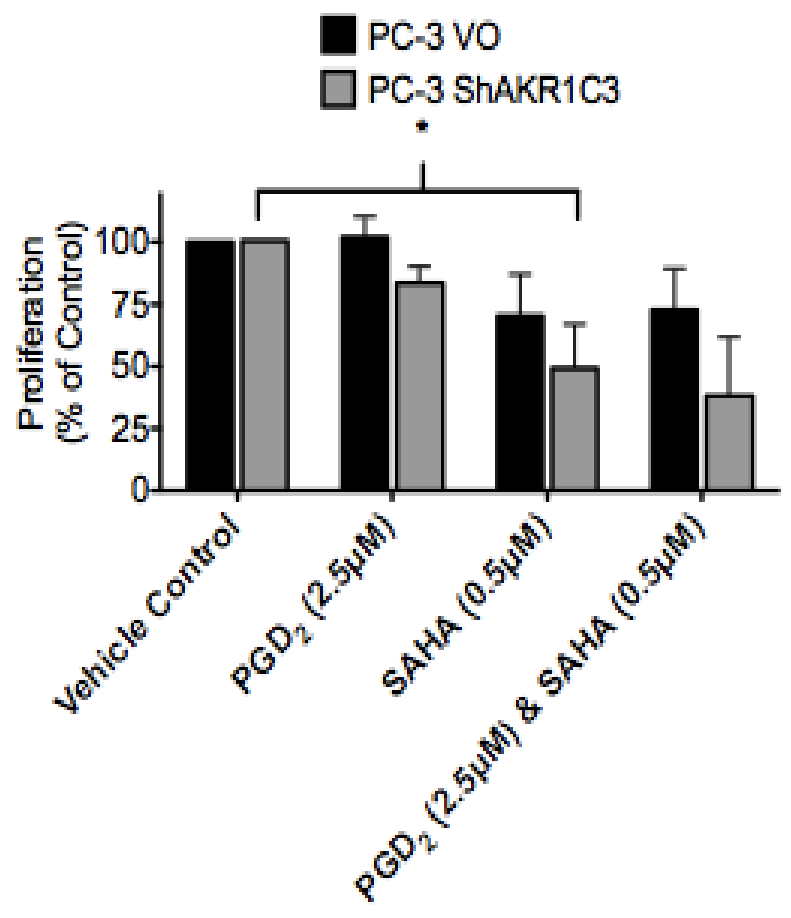

Treatment
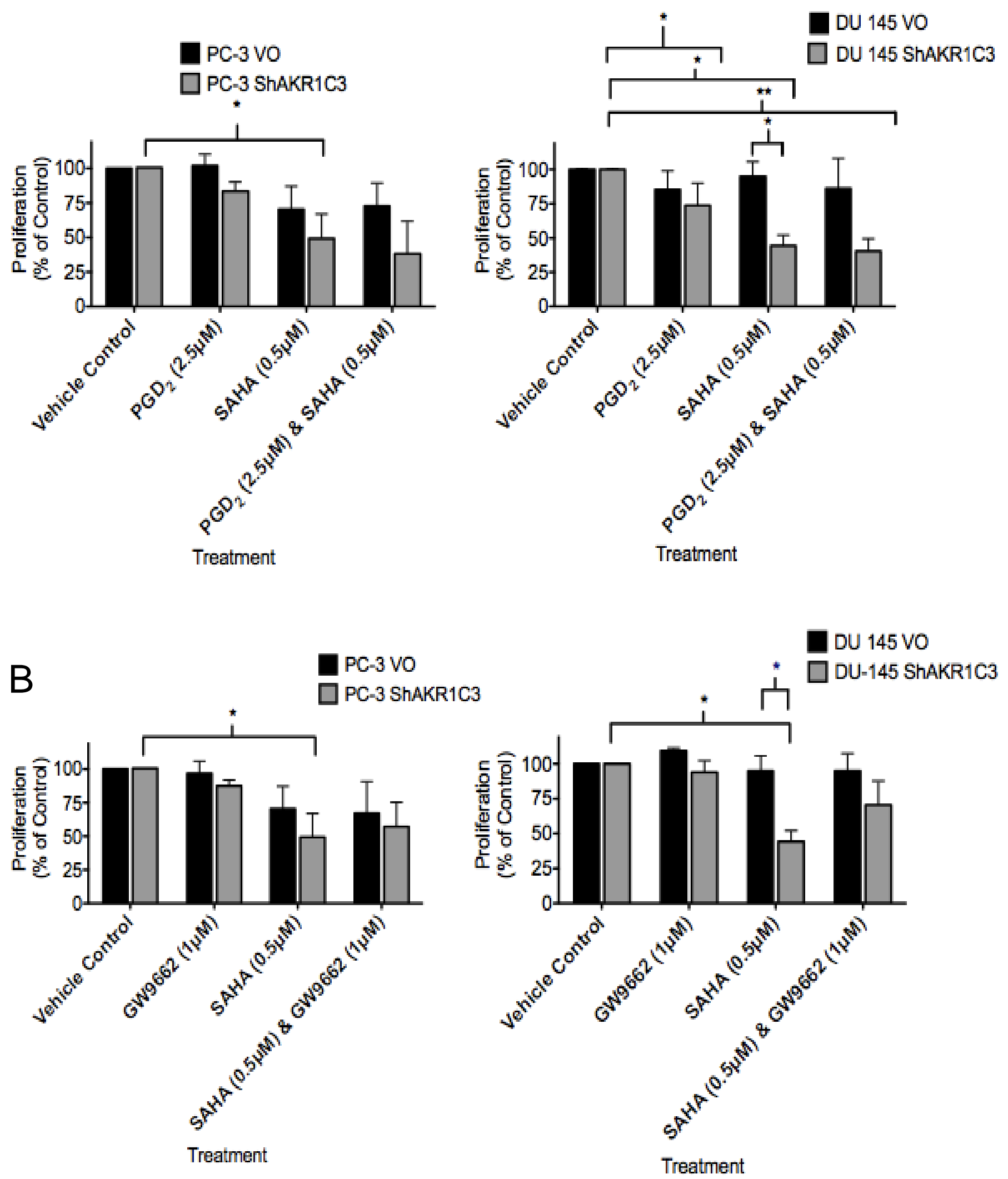

Figure 3 


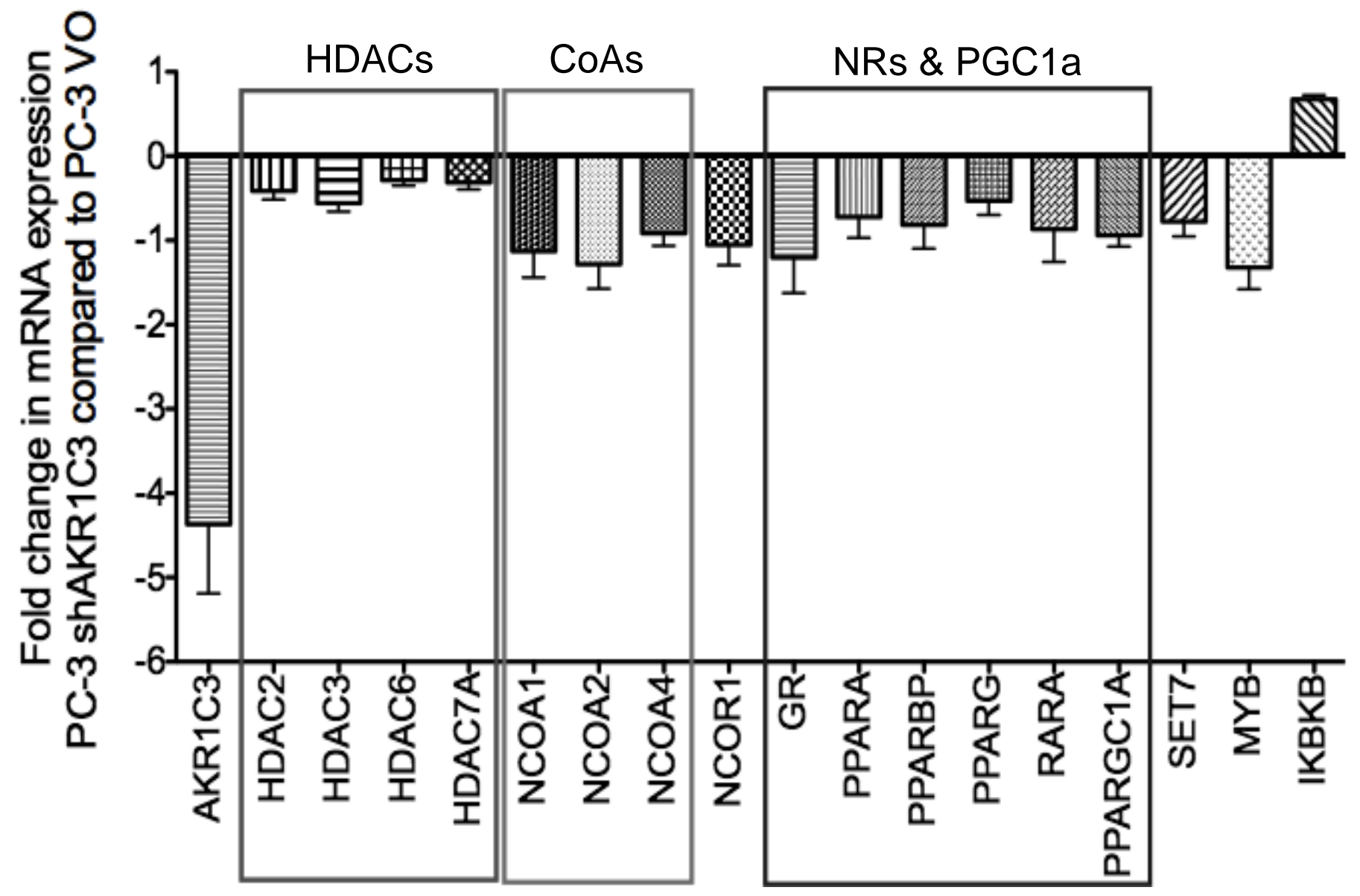

Figure 4 


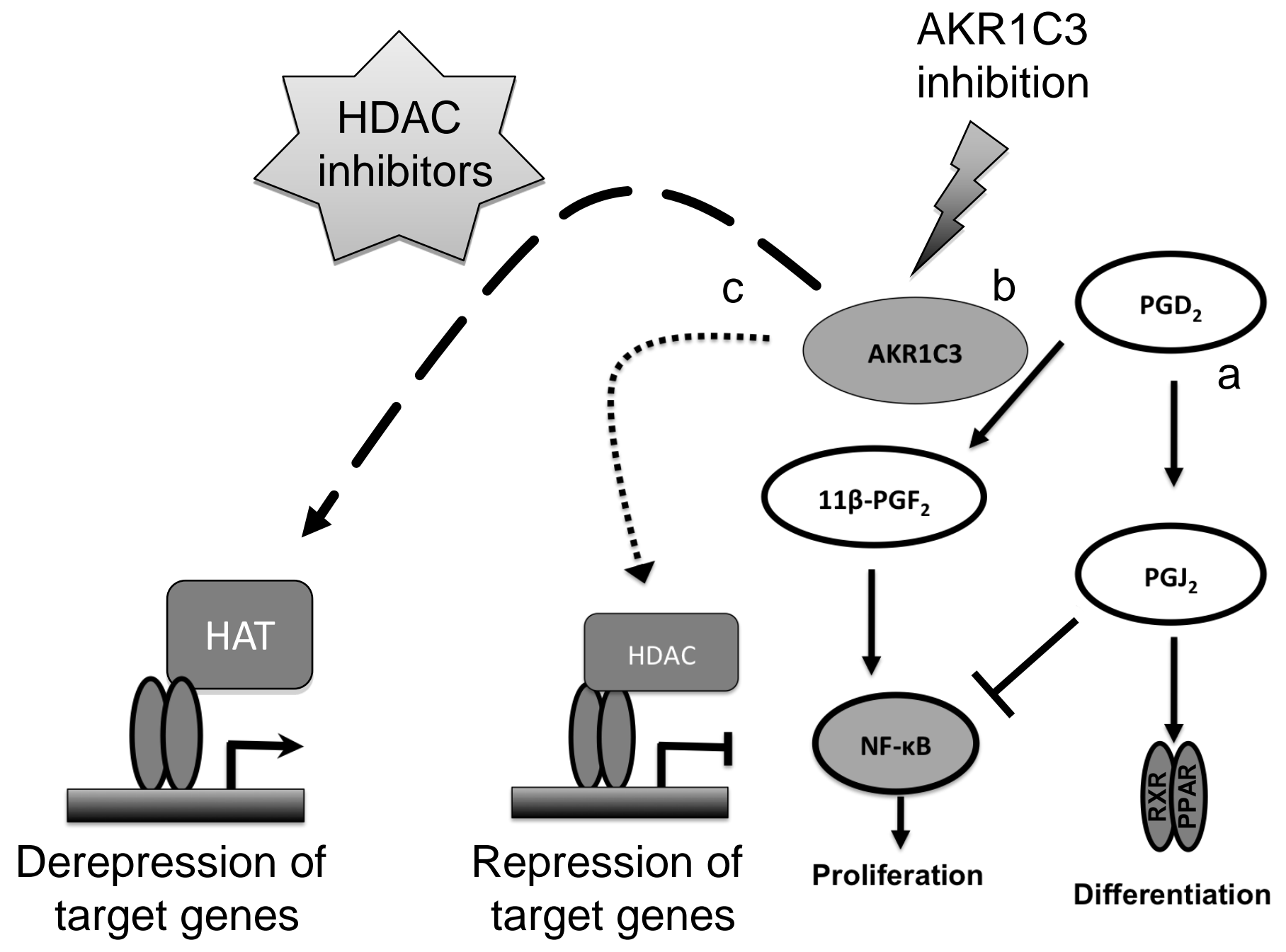

Figure 5 